\title{
Online Business Games in the Insurance Industries - An Attempt to Prepare Attendees for their Later Working Life as Self-employed Workers
}

\author{
P. Blum \\ inside Business Group, Aachen, Germany
}

\begin{abstract}
In Europe, the basic education for sales personnel in the insurance industries is regulated by law to guarantee a secure customer oriented sales process. This education mainly targets insurance-knowledge, -law, -conditions and the sales process. It does not prepare the attendees for their working life as a self-employed worker. To overcome this problem online business games are used because of their abilities to master complexity, to achieve higher cognitive objectives, to learn from mistakes without risk through trial and error, and to learn from operating experience through time-lapse. On the basis of the online business game "SiVA" - a simulation of an insurance agency - the impact on the future working life of a self-employed worker in the insurance industries is discussed and documented through a survey in one of the leading insurance companies in Germany.
\end{abstract}

Index Terms-Online Business Game, Serious Games, Business Simulation, Learning by Experience.

\section{INTRODUCTION}

In Europe, the basic education for sales personnel in the insurance industries is regulated by law to guarantee a secure customer oriented sales process. This education mainly targets insurance-knowledge, -law, -conditions and the sales process. In Germany approx. $78 \%$ of the insurance agents are self-employed and bound exclusively to one insurance company.

The above described education does not prepare the attendees for their working life as a self-employed worker. Most of the critical topics for the management of an insurance agency like time management, selfmanagement, business planning and leadership are not part of the education or treated only in theory. The theoretical knowledge that is gained within the basic education does not suffice to recognise the interrelationship between decisions and actions and the effects they have on the daily work in an agency.

\section{A. Business games and working life}

Online business games as a form of gaming simulation offer an excellent opportunity to shed considerable light on the network of business and economic interrelationships in complex systems of reality, such as in an insurance agency. Decisions will be taken on the course of action but the consequences thereof will only be action simulated, which means that an action can be tested without any risk. In the workplace this is rarely possible.

A further advantage of a business game is that the time between consequences and decisions can be shortened to whatever degree may be required simply by using time lapse and thus make it possible for a participant to "learn from experience”. In the real working life, however, errors and mistakes are frequently difficult to discover and the consequences mostly become apparent only a long time after they have been made. Business games thus make it possible to investigate systems that would be too slow, too expensive, too difficult or too risky to analyse in the real world.

With their main advantages such as mastering complexity, the achievement of higher cognitive objectives, learning from mistakes without risk through trial and error, learning from operating experience through time-lapse and particularly the strong learner motivation, business games can help mastering the future working life as a self-employed worker.

\section{SiVA ${ }^{1}$ - AN INSURANCE AgENCY SiMUlation}

An insurance agency is a complex system and has a considerable and many facetted interrelationship network of actions, events and consequences. In order to prepare learners in the insurance industry for their later working life as self-employed agents the online business game $\mathrm{SiVa}$ has been developed. In SiVa the learner runs an agency in simulation without any risks so he is able to learn from experience by means of trial and error.

\section{A. The principle of SiVa}

In the online business game SiVa the player assumes the role of an independent agent and manager of an exclusively bound insurance agency.

The situation within the agency is observed over a simulated time period of 18 months that commences in April. A month in reality is equivalent to one game period. The parameters that apply in the game are the working hours of the manager of the agency. They can be distributed in each round across a number of predetermined activities to be dealt with. Planning is completed for a week at a time, whereby the values are

\footnotetext{
${ }^{1}$ SiVa: German abbreviation for Insurance Agency Simulation
} 


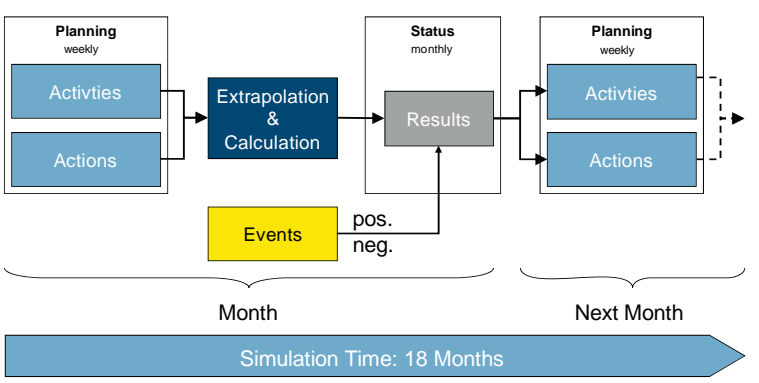

Figure 1. Simplified flowchart of the online business game SiVa

extrapolated to the mont h for calculating the performance of the agency (Figure 1). Each number of hours that can be invested is derived from the minimum number of working hours, i.e. 40 hours a week: but, just as in real life, these hours can be varied freely.

\section{B. Activities and Factors}

The consequences of the way in which activities are distributed in each round can be observed directly on the basis of the so called factors defined for the agency and then evaluated. The factors are the key figures used in the insurance business that present a clear picture of the success and the performance of the agency. A clear difference is made between quantitative (hard) factors and qualitative (soft) factors.

The quantitative key figures of the insurance agency describe directly the economically measurable performance of the agency. Primarily this is reflected in the production, i.e. in the total of the commissions that have been paid. Other very important indicators of the economic success are the amount of cancellations and the number of clients, since these are indicative of the chances of success of the agency over the long term (Figure 2, lower right table).

Quantitative Factors:

- New business

The production that has been generated by the activities within the framework of the acquisition of new clients.

- Business in force

The production that has been generated by the activities within the framework of doing business with clients the agency already has.

- Size of the portfolio

The number of policies in the agency's portfolio.

- Volume of the portfolio

The current volume in units of the policies in the agency's portfolio.

- Increase of the portfolio

The increase of the volume of the portfolio derived from total production of the business in force minus cancellation in a year with reference to the average production of the business in force.

- Applications cancelled

The cancellation proportion of production of the new business within the liability period in which a certain proportion of the commission has to be paid back.

- Policies cancelled

The cancellation proportion of the production of the business in force within a year with reference to average production of the business in force.

The soft facts held by the insurance agency cannot be collected directly; they reflect qualitative evaluation and also play a crucial role in the economic success of the agency. There is, for example, motivation as an indicator of one's own satisfaction. This factor has an effect on the willingness to perform and will thus effect over the longer term the performance of the insurance agency. Personal qualification is also an indicator for the quality of the work and thus also influences the agency's results (Figure 2, upper right table).

Qualitative Factors:

- Agency Manager - Motivation

The readiness of the manager of the agency to participate actively in the daily work of the agency

- Agency Manager - Qualification

The qualification of the agency manager with reference to sales and expert knowledge of insurance

- Quality Follow-up Visits:

The key figure indicating the quality with which visits are reworked.

The manager of the agency can utilise the available time of at least 40 hours per week in the following ways (Figure 2, left tables):

\section{- Agency Meetings}

The time expended for conferences with the company, reporting, marketing and the planning of strategies, dealing with formal minutes, etc.

- Office Organisation The time required for activities that are not directly connected with planning or preparation for customer calls: such activities might be the evaluation of written communications, telephone calls, weekly, monthly and annual planning, controlling, etc.

- Scheduling

The time spent on planning appointments of all types, customer calls included. These might imply, above all, the checking of recommendations for possible future business.

\section{- Preparation for Meetings}

The time spent for all the activities associated with preparing for customer calls. Such activities might include research, completion of a draft policy, etc.

- Preparation of draft policies and their evaluation The time spent on activities associated with the completion and evaluation of draft policies. Such activities might include the selection of information, setting out a sales strategy or a needs analysis.

- Promotion

The time spent on activities associated with presenting oneself, the agency or the insurance company with the aim of projecting and maintaining a positive public image.

- Further training

The time that the agency manager devotes in personal further professional development. This might include utilization of e-learning opportunities, attendance at seminars, obtaining further qualifications by 
examination, private measures to develop one's knowledge, reading specialist publications, etc.

- Time for acquiring new clients

The time devoted to client support and sales in the case of new clients. This might include aggressive business recommendations, clients recommend other possible clients, financial analysis, telephone client acquisition, etc.

- Number of used addresses

- Number of scheduled appointments on the basis of the addresses

- Number of scheduled visits on the basis of the addresses

- Number of used recommendations

- Number of scheduled appointments on the basis of the recommendations

- Number of scheduled visits on the basis of the recommendations

- Time for policy acquisition and retention

The time devoted to client support, advice and sales in the case of existing clients. This might include service visits, sales meetings, following up recommendations, financial analysis, revitalising policies in danger of cancellation, etc.

- Number of used contacts

- Number of scheduled appointments

- Number of scheduled visits

\section{Actions and Events}

A further possibility for the player to influence the simulation process in order to maximise the economic success of the insurance agency are specific actions. During the entire simulation a number of different actions are available to the agency manager, for example.

- Seasonal Actions,

- Advertising,

- Attendance at a training course,

- Informational presentations,

- Holidays, etc.

The costs that will be incurred by the agency for such actions will vary from action to action and these will have to be met by the income generated up to the time that such an action is initiated. In addition the agency manager may have to devote more time to a specific action and this time must also be taken into account. If the time for a specific action is the correct one and if it is a success, it will have an effect on a number of different factors such as new business or business in force, either in a restrictive way or in a beneficial way.

In the course of the game a number of events will occur by chance. These include:

- Insolvency of one of the largest employers in the agency's region,

- Changes to the law relating to insurance,

- Adjustment of premiums by the insurance company,

- Reorganization of policies already issued,

- Sickness,

- Natural phenomena etc.
Such events influence the current status of the insurance agency by changing factors, e.g. laps rates, the turnout or the portfolio of the agency. The learner must counteract the negative effects on the economic health of the agency by skilfully altering company strategy or by introducing certain actions.

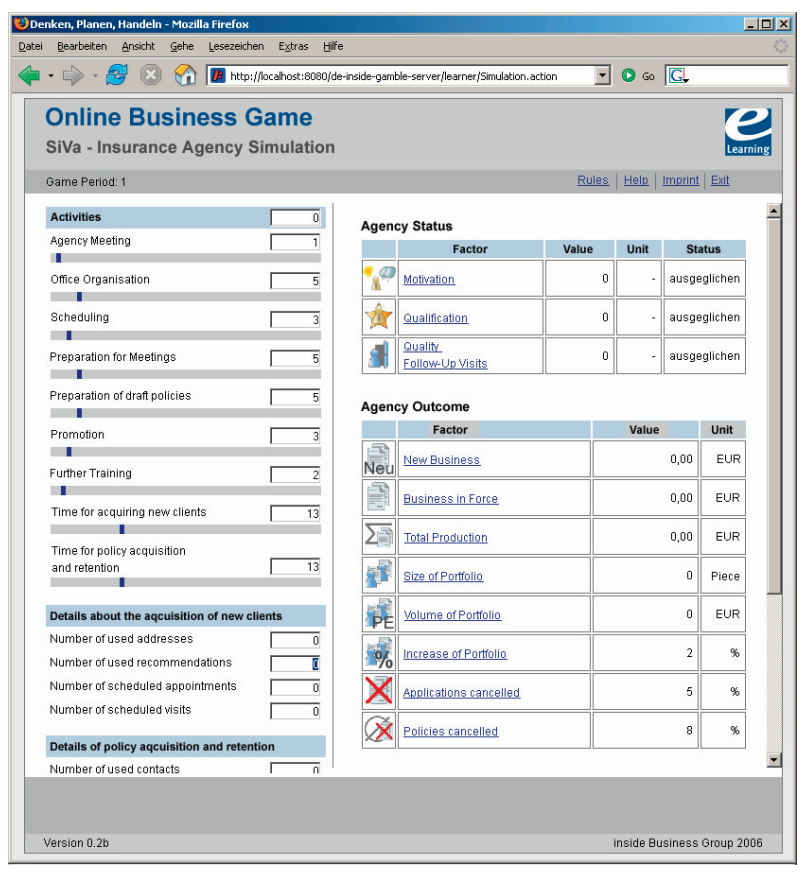

Figure 2. The graphical user interface of the SiVa

\section{EVALUATION OF SiVA}

The online business game SiVa was developed with the support of experts of four leading insurance companies in Germany: the Allianz Lebensversicherungs-AG, the Alte Leipziger Lebensversicherung a.G., the Concordia Versicherungsgesellschaft a.G. and the Signal Iduna Gruppe. The knowledge and the experience of these experts were essential to create an interrelationship network that mimics reality close enough to be useful to prepare the players for their working life.

To check if the simulation is sound a study with 34 prospective agents was conducted by one of the above mentioned companies.

\section{A. Setup}

For the study a blended learning scenario was designed to provide a comfortable and effective learning environment (Figure 3).

The scenario began with a two day opening session. On the first day it started with a motivation for the study, its goals and the learning objectives for the attendees. The etutors were introduced and the learners were split up into 3 groups of 8 and one group of 10 people. For the rest of the day $\mathrm{SiVa}$ was played in a plenary session to introduce the online business game and to make the learners familiarize with the concept, the rules and the functions. This warm up session should also deliver a first insight of the working live as a self-employed agency manager.

On the second day of the opening session the basic principles of time management and self-management were presented with the focus on insurance agencies. After that the main activities and key figures of an insurance agency 
and their dependencies were worked out. With new knowledge and perceptions the learners went into their group to play $\mathrm{SiVa}$ again. At the end of the opening session the SiVa contest was introduced to the learners. A prize was awarded to the best three agency managers. The first prize was a Blackberry, the second prize was a briefcase and the third was a first-class pen. The ranking was automatically calculated by $\mathrm{SiVa}$ on the basis of the total production, the size of the portfolio and the rate of the applications and policies cancelled of the agency.

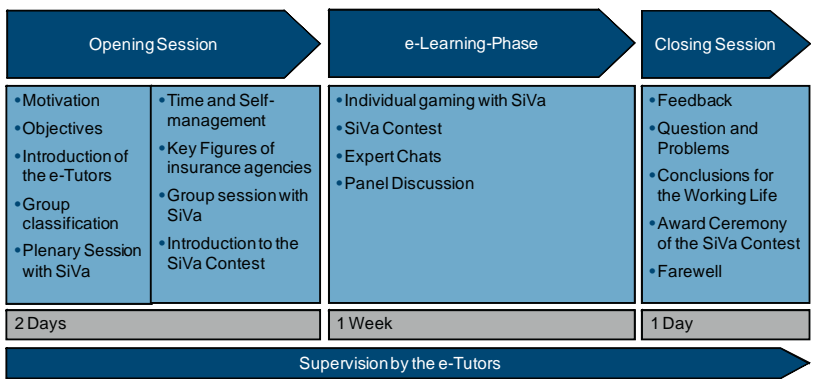

Figure 3. Concept of the Blended Learning Scenario for the study

Highly motivated the attendees started into the e-learning phase of the blended learning scenario. During the week the learners had unlimited access to the online business game SiVa. They were supervised by the e-tutors who answered the learner's questions and gave advice when it was requested. Additionally the learners had the opportunity to attend panel discussions or expert chats to optimize their agency strategy.

In the closing session open questions were answered and problems which have occurred were discussed. Based on the experience with the online business game $\mathrm{SiVa}$ conclusions were drawn for the working life of the future agency managers. After the awards ceremony the winner's course of the game was replayed and analysed.

\section{B. Evaluation}

Prior to the opening session and after the closing session a questionnaire was provided to the learners. The first queried the expectations and the previous knowledge of the attendees and the closing one requested the feedback about the business game and the preliminary estimate of the outcome for the future working life. Three month after the study a third questionnaire was sent to the now self-employed agency managers to check if the predicted outcome has come.

Unfortunately it was not possible to complete the evaluation prior to the submission of this paper because not all the needed data was available. Thus only the first findings are presented in this paper.

The first step was to find out if there was a correlation between the success of the attendees' simulated agency with either the experience of the attendee with business games, e-learning and agency management. Hence the following questions where stated in the questionnaire prior to the opening session:

- “Have you ever played a business game before?”

- “Do you have experience with e-Learning?”

- "Do you have experience with insurance agency management?"
The answers of the learners (Figure 4 to Figure 6) were tested for correlation with the values of the ranking at the end of the contest.

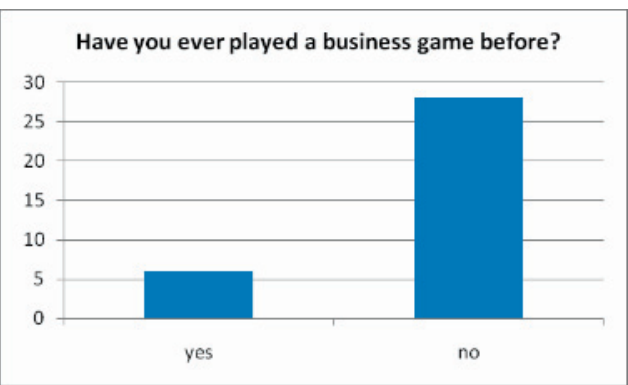

Figure 4. Answers to question 1 of the prepositioned questionnaire.

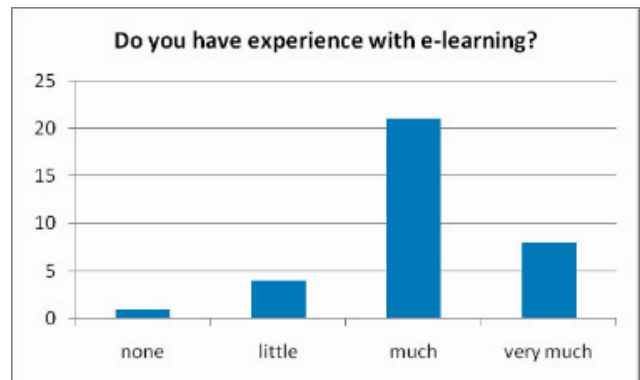

Figure 5. Answers to question 2 of the prepositioned questionnaire.

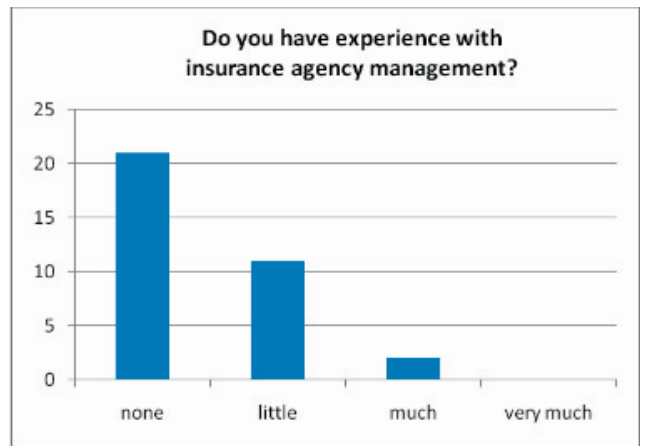

Figure 6. Answers to question 3 of the prepositioned questionnaire.

In all three cases there was no significant correlation. In case two there was a very slight correlation of 0.26 . In case three we assume that the number of persons with experience in agency management was too low. Therefore we decided not to conclude anything in this case. For the first two cases we concluded that you don't need to be an experienced player of business games or have experience with e-learning to successfully complete the simulation. But we presume that experience with e-learning helps to play the business game because the experienced players have completed more simulations than the others.

Another question of the preceding questionnaire was about the expectation of the attendees if a business game could prepare them for their later working life (Figure 7). Taken this answers into account analyzing the question of the follow-up questionnaire after three month, if the business game helped in real to prepare for the later working life (Figure 8), we can identify a change of mind. A large part of the attendees hold that SiVa prepares indeed for the later working life as a self-employed worker in the insurance industries. 


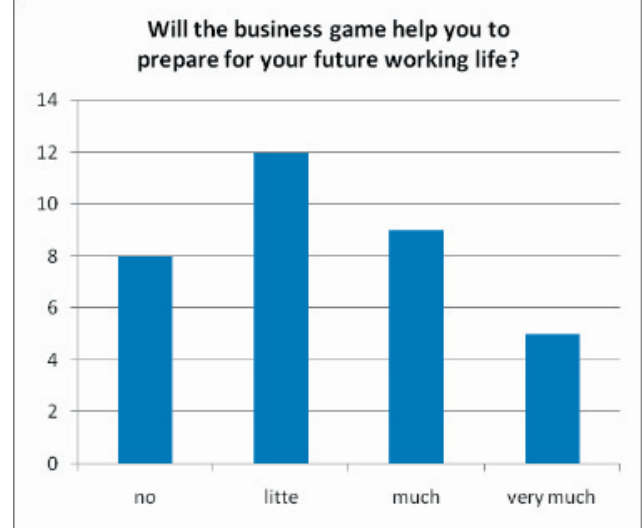

Figure 7. Answers to question 4 of the prepositioned questionnaire.

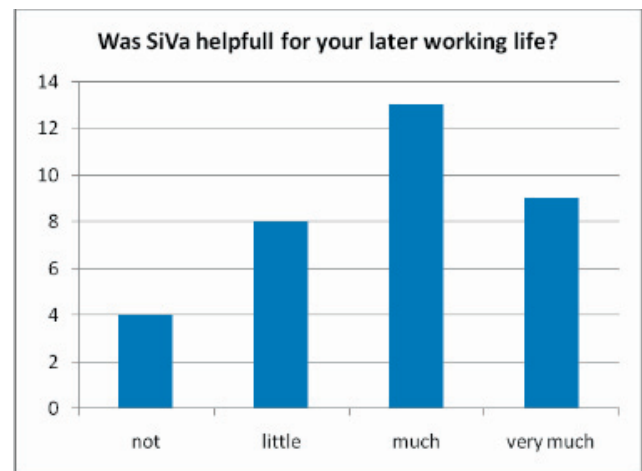

Figure 8. Answers to question 1 of the follow-up questionnaire.

Consecutively the real business outcome in conjunction with the results of the simulation was examined to prove the above stated option of the attendees. On the basis that an amount of more than 95.000 points as a score at the end of the simulation is the threshold to call the player successful it could be shown, that an effective learner also succeeded in the first three month of his later working life. On the basis of the finale score 20 of the 34 learners (41\%) are classified as good. $75 \%$ of them were classified as high performer on the basis of their economic results of the insurance agency (Figure 9).

The comparison of the learners classified as average performers or better with a group of attendees that had not participated in this blended learning scenario also showed that the average economic outcome after the first 3 month was approximately $12 \%$ higher.

\section{SUMMARY AND CONCLUSION}

The online business game SiVa is a useful extension of the existing e-learning mix in corporate learning. It offers an excellent opportunity to shed considerable light on the network of business and economic interrelationships in an insurance agency. It allows decision making by observing the consequences without any risk which is rarely possible in real working life.

The first results of the study show that a business game can be presented even to inexperienced learners in terms of e-learning and gaming.

Success in the simulation correlates with success in the first three month of the working life.
The study showed that a learning scenario with the online business game $\mathrm{SiVa}$ is able to prepare attendees for their later working as a self-employed agency manager in the insurance industries.

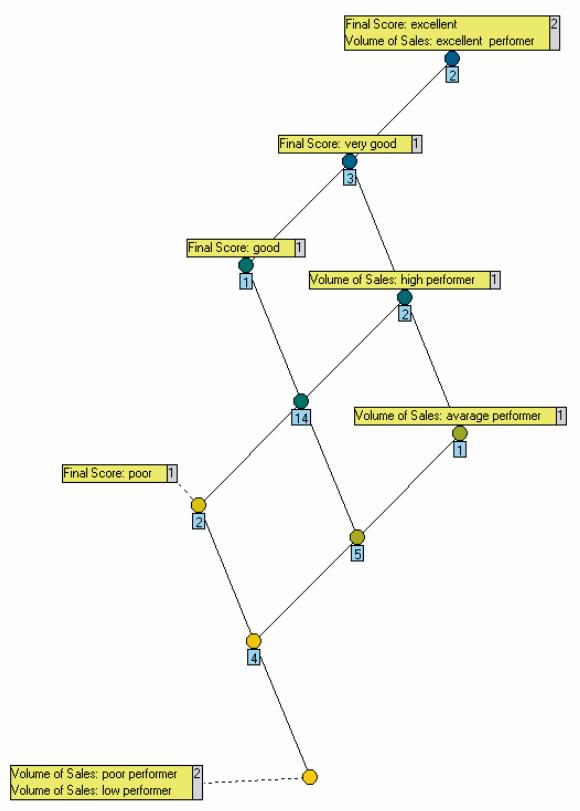

Figure 9. Cernato diagram of the correlation between final score and economic outcome.

\section{REFERENCES}

[1] C. Aldrich, „Simulations and the Future of Learning: An Innovative (and Perhaps Revolutionary) Approach to e-Learning”, Pfeiffer, Somerset, 2003.

[2] M. Beenken, „Der Versicherungsvertreter als Unternehmer“, 3. Auflage, Verlag Versicherungswirtschaft, Karlsruhe, 2002.

[3] M. Bossel, „Systeme, Dynamik, Simulation - Modellbildung, Analyse und Simulation komplexer Systeme”, Books on Demand, 2004.

[4] GDV, Gesamtverband der Deutschen Versicherungswirtschaft, Statistics, 2008

[5] T. Geilhardt, T. Mühlbradt, „Planspiele im Personal- und Organisationsmanagement“, Verlag für Angewandte Psychologie, Göttingen, 1995.

[6] W.C. Kriz, "Creating Effective Interactive Learning Environments through Gaming Simulation Design”, in Journal of Simulation \& Gaming, vol 34, number 4, pp. 495-511, 2003.

[7] M. Prensky, “Digital Game-Based Learning”, Paragon House, St. Paul, 2003.

[8] S. Ritter, „Das Unternehmen Agentur, Erfolgreich selbständig in der Versicherungswirtschaft “, 2. Auflage, Gabler Verlag, Wiesbaden, 2005.

[9] M. Weber, „Kennzahlen Unternehmen mit Erfolg führen“, WRS Verlag Wirtschaft, Recht und Steuern, Planegg, 2001.

\section{AUTHOR}

P. Blum is with the inside Business Group, Aachen, Germany (e-mail: blum.patrick@inside-online.de).

Manuscript received 16 January 2008. Published as submitted by the author. 